\title{
Aline Zouvi
}

MOREIRA, Paulo. PASINI, Leandro. Modernismo localista das Américas: os contos de Faulkner, Guimarães Rosa e Rulfo. Belo Horizonte: Editora da UFMG, 2012.

Modernismo localista das Américas: os contos de Faulkner, Guimarães Rosa e Rulfo é um trabalho resultante da tese de doutorado de Paulo Moreira, concluída na Universidade da Califórnia, Santa Bárbara, em 2007. Publicada em livro em 2012 pela editora da UFMG, a obra promete aos estudiosos da forma conto - ou ficção curta, como também é denominada - uma nova abordagem do estudo do conto, ao propor a sua visão não de modo isolado, mas de modo que permita novas interpretações. Moreira introduz o livro sugerindo que a leitura do conto como unidade isolada e autossuficiente "não é a única estratégia possível" - sendo o olhar sobre o conjunto de contos, portanto, um condutor para "novas possibilidades críticas". Sua proposta, tal como ele a descreve em sua introdução ao livro, é promover a "discussão das possibilidades e implicações de uma hermenêutica do conto, de uma redefinição do modernismo baseada num estudo comparativo do termo". Para tanto, Moreira faz uso de um corpus de 15 contos publicados entre 1930 e 1960 por William Faulkner, João Guimarães Rosa e Juan Rulfo, buscando, em suas análises, "um olhar renovado sobre uma ficção atenta às particularidades do local" - o que Moreira denomina como localista.

O leitor pode se questionar, como ocorre com certa frequência no primeiro contato com estudos interligados e antologias, sobre o grau de aleatoriedade nas redes estabelecidas. Moreira aproxima os três autores pelos três eixos que elenca, a saber: o conto, o localismo e a estética 
narrativa moderna, constituindo um todo "que convida à interpretação", não deixando, no entanto, de classificar como "imaginária" a sua coletânea (e, mais adiante, como "impossível”), explicando ao leitor que o livro que tem em mãos se trata, de fato, de um exercício borgiano de uma construção crítica de redes integradas de textos, feita assim uma coletânea com contos dos três escritores selecionados entre inúmeras possibilidades, "que esperam por uma mente ociosa e inquisitiva para começar a existir criticamente". O conjunto de contos formado, assim como o livro gerado a partir dele, são, para o autor, "atos de amor genuíno pela literatura de Faulkner, Guimarães Rosa e Rulfo", reconhecidos como três dos maiores escritores das Américas no século XX.

À medida que avançamos na leitura de Modernismo localista das Américas, Moreira passa a revelar níveis mais intrincados de conexão entre os três autores, sendo o seu elo de identificação mais forte a presença, em seus contos, do contato sempre problemático, muitas vezes física e psicologicamente devastador, com os movimentos de modernização capitalista - Faulkner, Rosa e Rulfo oferecem um "mosaico magnífico das Américas", no qual o continente é palco para um drama humano que tem origem na chegada dos primeiros europeus às suas terras. Tal representação é feita por meio do trabalho de exploração imaginativa aos limites máximos das três línguas europeias em questão, assim como a abordagem detalhada e criativa de três locais "relegados às margens das margens", criando-se, quase simultaneamente, três cosmos literários "extraordinariamente ricos e complexos": Yoknapatawpha, no Mississippi, na obra de Faulkner; o sertão de Minas Gerais em Guimarães Rosa; e o Llano, Jalisco, em Rulfo.

O livro é dividido em duas partes: Na Parte I, "Percorrendo uma antologia imaginária”, são analisados os contos de Faulkner, Rosa e Rulfo selecionados, formulando-se um capítulo para cada um deles. Na Parte II, "Do local ao cosmos literário", Moreira apresenta os mundos dos três autores em três capítulos, seguidos de um quarto que traz reflexões de Moreira sobre as concepções dos próprios escritores sobre a criação de seus três cosmos. Nas considerações finais, são apresentadas formulações sobre o conto, a recepção crítica e o lugar de Modernismo localista das Américas, além de apontar, enfim, algumas considerações sobre os termos modernidade, moderno e modernismo, concluindo o livro com uma análise sobre o ("um") comparativismo das Américas.

Na primeira parte de Modernismo localista, Moreira analisa cinco contos de cada um dos escritores abordados, a saber: "The Tall Men", "The Hound", "Wash", "A Rose for Emily" e "A Bear Hunt", de William Faulkner; "Famigerado", "Os irmãos Dagobé”, “Corpo Fechado”, "Esses Lopes” e "São 
Marcos”, de Guimarães Rosa; e “iDiles que no me maten!”, “La Cuesta de las Comadres", "Es que somos muy pobres", "Talpa" e "El día del derrumbe", de Juan Rulfo. Os contos são distribuídos de modo que a sua sequência seja composta por cinco agrupamentos contendo um conto de cada autor. Moreira afirma ao leitor queas análises podem ser lidas em qualquer ordem, porém dá-se conta de que, na medida em que as análises são feitas, há o surgimento de referências às análises dos contos anteriores, seja devido ao encontro de pontos comuns ou contrastantes, revelando detalhes dos enredos e das personagens comparadas que sugerem a demanda de uma leitura feita linearmente. A presença de referências cruzadas, no entanto, dificilmente atrapalhará a leitura deliberada de capítulos esparsos, ou mesmo em trios, como a sua disposição no índice sugere. Os capítulos de Paulo Moreira lembram a própria estrutura do conto - têm um número reduzido de páginas e comprimem um teor alto de conteúdo, cuja significação acaba se concentrando mais na contextualização dos universos dos autores e nos impasses encontrados por eles que no objeto conto. Os elementos biográficos presentes nos capítulos, no que se refere ao trajeto do texto até o leitor (sua concepção, impasses na publicação, etc.) são mais fortes naqueles sobre Faulkner, e sua presença decresce nos textos sobre Rulfo, sendo os sobre Rosa aqueles com menos informações de tal teor.

Textos também curtos descrevem o universo de cada autor abordado, na segunda parte do livro, nos quais Moreira descreve historicamente a fundação das cidades que constituem os universos em questão, exibindo os mapas que registram não Mississippi, mas a Mississippi de Absalom, Absalom! ou as Minas Gerais de Guimarães Rosa. Dedicando o primeiro capítulo a Faulkner, o segundo a Rosa e o terceiro a Rulfo, Moreira revela um trabalho extenso sobre as peculiaridades históricas e econômicas que constituíram os ambientes indissociáveis dos autores e de suas obras, trabalho este ("exaustivo e amoroso", como reforça) já presente ao longo das análises feitas na primeira parte de Modernismo localista. No quarto capítulo desta segunda parte, intitulado "Nadando contra a corrente", Moreira comenta os ensaios curtos dos próprios escritores focalizados - "Mississippi", "Minas Gerais" e "La tierra pródiga”, respectivamente -, os quais, apesar de expressarem-se ao público raramente fora de sua ficção, mostram a postura "cética, mas afetiva" implícita em suas obras ficcionais.

Modernismo localista das Américas fornece um novo olhar para o formato conto à medida que potencializa o seu grau de abertura e seu caráter inter-relacional. Cabe explorar, no entanto, esta noção de novo olhar e colocá-la em prática nas análises dos contos. 